\title{
Is conventional aortic arch surgery justifiable in octogenarians?
}

\author{
Kenji Minatoya, MD, Hitoshi Ogino, MD, Hitoshi Matsuda, MD, Hiroaki Sasaki, MD, Hiroshi Tanaka, MD, \\ Junjiro Kobayashi, MD, Toshikatsu Yagihara, MD, and Soichiro Kitamura, MD
}

Objective: Although the surgical result of conventional aortic arch replacement has been improved with sophisticated techniques, it is still a deeply invasive procedure. On the other hand, advanced age has been reported as a factor of increased morbidity and mortality in patients undergoing cardiovascular surgery. The number of octogenarians, however, is steadily increasing. The aim of this study is to analyze the outcome of aortic arch surgery in octogenarians.

\begin{abstract}
Methods: From January 1995 to September 2007, 113 octogenarians and 1 nonagenarian underwent aortic arch replacement (mean age, $83.0 \pm 2.5 ; 60 \mathrm{men}$ ) in our institute. All patients underwent surgery under hypothermic circulatory arrest. The lowest body temperature during circulatory arrest was below $22^{\circ} \mathrm{C}$ until 2001 and $28^{\circ} \mathrm{C}$ after 2002. Antegrade selective cerebral perfusion or retrograde cerebral perfusion was used as an additional brain protection technique. Emergency operations were performed in $37(32.5 \%)$ patients; of them, $28(75.7 \%)$ were for acute aortic dissection. Seventy-four $(64.9 \%)$ patients underwent total arch aortic replacement and the other $40(35.1 \%)$, hemiarch aortic replacement. Concomitant operations consisted of aortic root replacement in 1 patient, aortic valve replacement in 4, and coronary artery bypass grafting in 25 .
\end{abstract}

Results: The average duration of circulatory arrest, myocardial ischemic time, and pump time was $57 \pm 21,123$ \pm 45 , and $224 \pm 80$ minutes, respectively. The total hospital mortality was $7.9 \%(9 / 114), 5.2 \%(4 / 77)$ for elective operations and $13.5 \%(5 / 37)$ for emergency operations $(P=.12)$. The hospital mortality was $19.2 \%(5 / 26)$ until 2001 and decreased to $4.5 \%(4 / 88)$ after $2002(P=.015)$. Eleven $(9.6 \%)$ of the 114 patients had a perioperative stroke, and $8(7.0 \%)$ had transient neurologic dysfunction. Other complications were respiratory failure in $17(14.9 \%)$ patients, bleeding in $6(5.3 \%)$, gastrointestinal tract problems in $3(2.6 \%)$, and mediastinitis in $1(8.8 \%)$ patient. Chronic obstructive pulmonary disease was a multivariate predictor $(P<.05)$ of hospital death and emergency operation was a predictor of perioperative stroke. The postoperative 1-year survival was $84.8 \%$, the 3-year survival was $68.5 \%$, and the 5 -year survival was $58.1 \%$.

Conclusions: The outcome of conventional aortic arch surgery in octogenarians is improving. The operations were performed with an acceptable operative risk even under emergency situations, including acute aortic dissection. The conventional surgical option for aortic arch diseases should not be abandoned only because of the high chronologic age of the patient. (J Thorac Cardiovasc Surg 2010;139:641-5)

Despite recent important advances in surgical techniques, conventional aortic arch replacement remains a highly invasive procedure. On the other hand, advanced age has been reported as a factor of increased morbidity and mortality for patients undergoing cardiovascular surgery. It is usually assumed that the outcomes of aortic surgery in elderly patients are poorer than those in the younger population. The number of octogenarians, however, is steadily increasing

\footnotetext{
From the Department of Cardiovascular Surgery, National Cardiovascular Center, Osaka, Japan.

Disclosures: None.

Read at the Eighty-eighth Annual Meeting of The American Association for Thoracic Surgery, San Diego, California, May 10-14, 2008

Received for publication July 8, 2008; revisions received Oct 1, 2009; accepted for publication Nov 3, 2009.

Address for reprints, Kenji Minatoya, MD, Department of Cardiovascular Surgery, National Cardiovascular Center, 5-7-1 Fujishirodai, Suita, Osaka, 5658565 Japan

(E-mail: minatoya@hsp.ncvc.go.jp).

$0022-5223 / \$ 36.00$

Copyright $(c) 2010$ by The American Association for Thoracic Surgery

doi:10.1016/j.jtcvs.2009.11.008
}

in developed countries. ${ }^{1}$ The aim of this study is to review and analyze the outcomes of aortic arch surgery in octogenarians.

\section{PATIENTS AND METHODS \\ Patients}

From January 1995 to September 2007, 113 octogenarians and 1 nonagenarian underwent aortic arch replacement (mean age, $83.0 \pm 2.5 ; 60$ men) under hypothermic circulatory arrest through a median sternotomy in our institute. Figure 1 shows the distribution of the patients by age. The lowest body temperature during hypothermic circulatory arrest was below $22^{\circ} \mathrm{C}$ until 2001; however, the temperature was gradually raised up to $28^{\circ} \mathrm{C}$ after 2002. Antegrade selective cerebral perfusion (ASCP) or retrograde cerebral perfusion (RCP) was used as an additional brain protection technique. RCP was used in 6 patients until 1999, and ASCP was used in all but those 6 patients in this series. Fifty-two patients had distal arch aneurysm and 2 had pseudoaneurysm at the distal arch after graft replacement of the aorta. Emergency operations were performed in $37(32.5 \%)$ patients, and of them 28 $(75.7 \%)$ were for acute aortic dissection. Seventy-four $(64.9 \%)$ patients underwent total arch aortic replacement, and the other $40(35.1 \%)$ were subjected to hemiarch aortic replacement.

Our institution approved this retrospective study and waived patient consent requirements provided patients could not be identified. 


\section{Abbreviations and Acronyms \\ ASCP $=$ antegrade selective cerebral perfusion \\ $\mathrm{RCP}=$ retrograde cerebral perfusion}

\section{Operative Techniques}

All operative maneuvers were performed through a median sternotomy. A short left hemicollar incision was also made to improve exposure of the branches of the aortic arch.

The femoral artery or ascending aorta was used as a site of cannulation for arterial return. Ascending aortic cannulation is preferable when atherosclerotic change in the ascending aorta is minimal on epiaortic echography, although femoral arterial cannulation is selected when the ascending aorta has severe atherosclerotic changes or in the presence of acute aortic dissection. The right axillary artery was additionally cannulated in patients operated on after 2000. The patients were cooled using the $\alpha$-stat method of pH control until the nasopharyngeal temperature reached $20^{\circ} \mathrm{C}$ or $28^{\circ} \mathrm{C}$. Reperfusion and rewarming were always performed in antegrade fashion through the side branch of the graft. A collagen woven or gelatin-impregnated knitted Dacron graft was used for graft replacement. One branched graft was used for hemiarch replacement and a quadrifurcated graft for total arch replacement. When total arch replacement was performed, arch vessels were independently reconstructed with a quadrifurcated graft without en bloc repair technique.

Open distal anastomosis was performed in all cases. The anastomosis was always performed with complete transection of the descending aorta distal to the left subclavian artery for total arch replacement and with complete transection of the aortic arch for hemiarch replacement. The stepwise technique was used for distal anastomosis in most patients subjected to total arch replacement. A short graft was introduced into the lumen of the descending aorta from the stump and then sewn to the aortic wall with 3-0 or 4-0 polypropylene running suture. The short graft was then pulled out

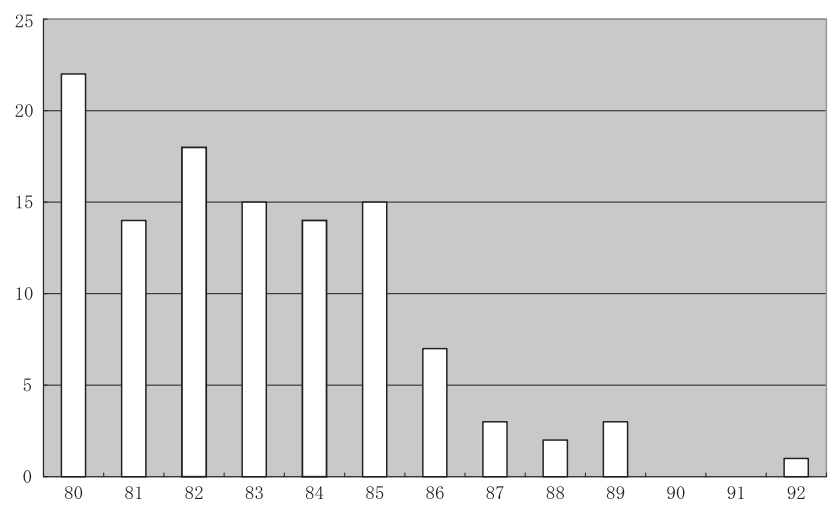

FIGURE 1. Age distribution of all patients.

of the descending aorta. At the suture line, the graft was inverted circumferentially and fixed to the aortic wall in appropriate fashion. Finally, the quadrifurcated graft was anastomosed to the short graft with 3-0 polypropylene running suture. This was followed by anastomosis of the left subclavian artery, proximal anastomosis to the ascending aorta, reconstruction of the left internal carotid artery, and final anastomosis of the brachiocephalic artery.

ASCP was performed with an ordinary arterial cannula in the right axillary artery or with a balloon-tipped cannula inserted directly into the brachiocephalic artery from inside the aortic arch and in the left common carotid artery. The left subclavian artery was clamped when the nasopharyngeal temperature was below $25^{\circ} \mathrm{C}$, and it was perfused with a balloon-tipped cannula when the temperature was above $25^{\circ} \mathrm{C}$. ASCP was continued until all arch branches were reconstructed. Cerebral perfusion was regulated to maintain the mean pressure in the superficial temporal arteries at around $60 \mathrm{~mm} \mathrm{Hg}$. The perfusion pressure in bilateral superficial temporal arteries was monitored in most cases. However, perfusion pressure measured at the top of the perfusion balloon was used when the temporal arteries were not available.

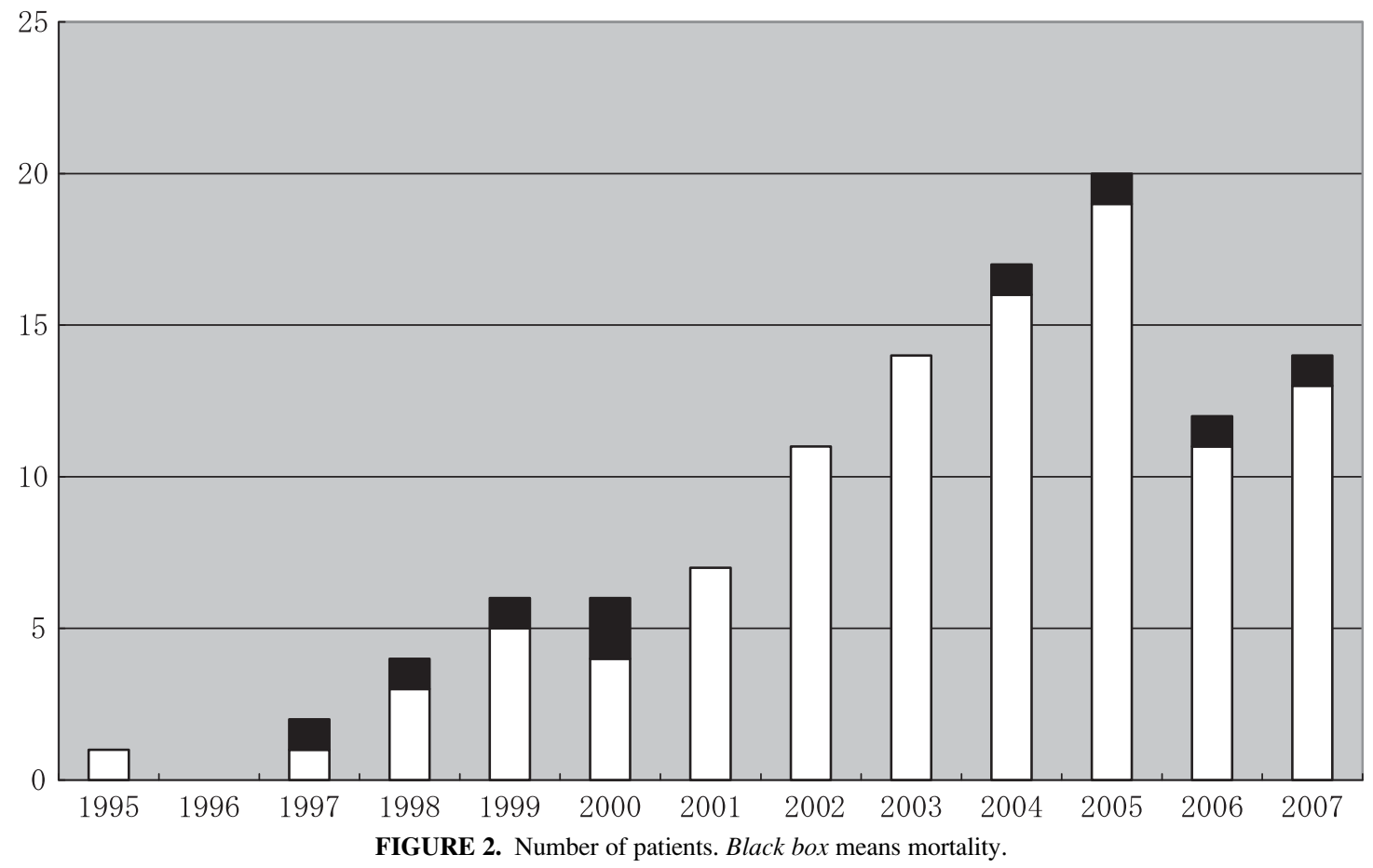


For reinforcement of the stump of the aorta in case of acute aortic dissection, gelatin-resorcin-formaldehyde glue or BioGlue surgical adhesive (CryoLife, Inc, Kennesaw, Ga) was usually applied to obliterate the false lumen. In addition to the use of chemical glue, all stumps were reinforced with Teflon felt strips. For total arch replacement, Teflon felt strips were placed on the outer side of the aortic stump and a graft 5 to $7 \mathrm{~cm}$ in length and 18 to $22 \mathrm{~mm}$ in diameter was inserted into the true lumen of the descending aorta as an elephant trunk. They were sutured and fixed with 5-0 polypropylene running suture, obliterating the false lumen in a sandwich-like fashion. The quadrifurcated graft was anastomosed to the stump of the descending aorta, where sandwich-like reinforcement was applied. For hemiarch replacement, Teflon felt strips were placed on the outer and inner sides of the aortic stump. The stump was thus reinforced and the false lumen obliterated in sandwich-like fashion with 5-0 polypropylene running suture.

\section{Concomitant Procedures}

Concomitant procedures included aortic valve resuspension in 28 patients, aortic valve replacement in 4 , and coronary artery grafting in 25 patients.

\section{Definitions}

Hospital mortality was defined as death within the hospital. Postoperative stroke was defined as newly developing neurologic deficit, confirmed by computed tomography. Transient neurologic dysfunction was defined as postoperative confusion, agitation, delirium, or prolonged obtundation with negative brain computed tomographic findings and complete resolution before discharge. The neurologic diagnosis was made by neurologists.

\section{Statistical Analysis}

Values are presented as the mean \pm standard deviation. Data were analyzed by the $\chi^{2}$ test for categorical variables. Factors that tended to be of statistically significant risk by univariate testing $(P<.10)$ were entered into a multivariate analysis. Stepwise logistic regression analysis of predictor variables for hospital mortality and stroke was performed with estimate odds ratios and $95 \%$ confidence intervals for each of the independent variables in the model. The Kaplan-Meier estimate was used to depict survival over time.

\section{RESULTS}

The average duration of circulatory arrest, myocardial ischemic time, and pump time was $57 \pm 21$ minutes, $123 \pm 45$ minutes, and $224 \pm 80$ minutes, respectively.

The total hospital mortality was $7.9 \%(9 / 114), 5.2 \%$ (4/ 77) for elective operations and $13.5 \%$ (5/37) for emergency operations $(P=.12)$. All patients stayed in our hospital to the end. The average length of hospital stay of the patients was $36.8 \pm 26.1$ days (1-89 days, median 33.9 days). The 30 -day mortality was $2.6 \%$ (3/114). The cause of death was sepsis in 3 patients, low output syndrome in 1, rupture of residual aneurysm in 1, respiratory failure in 2, and gastrointestinal tract problems in 2 . The hospital mortality was $19.2 \%$ (5/26) until 2001 , and it decreased to $4.5 \%$ (4/ $88)$ after $2002(P=.015)$. Figure 2 shows the number of patients distributed by year and the number of deaths in each year. There were 19 patients aged 86 years and older. The hospital mortality of the 19 patients was $9.7 \%$, and that of the rest of the younger patients was $7.2 \%(P=.67)$.

In total, $11(9.6 \%)$ patients had a perioperative stroke, $6.5 \%(5 / 77)$ associated with elective operations and $16.2 \%$
TABLE 1. Univariate analysis of risk factors for hospital death

\begin{tabular}{|c|c|c|}
\hline Variables & No. & $P$ value \\
\hline \multicolumn{3}{|l|}{ Operation } \\
\hline Total arch replacement & $7 / 74$ & .40 \\
\hline Hemiarch replacement & $2 / 40$ & \\
\hline \multicolumn{3}{|l|}{ Urgency } \\
\hline Elective & $3 / 76$ & .03 \\
\hline Emergency & $6 / 38$ & \\
\hline \multicolumn{3}{|l|}{ Concomitant operations } \\
\hline Yes & $2 / 41$ & .58 \\
\hline No & $5 / 73$ & \\
\hline \multicolumn{3}{|l|}{ Circulatory arrest } \\
\hline$>60 \min$ & $4 / 42$ & .62 \\
\hline$\leq 60 \mathrm{~min}$ & $5 / 72$ & \\
\hline \multicolumn{3}{|l|}{ Cardiac ischemic time } \\
\hline$\leq 3 \mathrm{~h}$ & $8 / 98$ & .79 \\
\hline$>3 \mathrm{~h}$ & $1 / 16$ & \\
\hline \multicolumn{3}{|l|}{ Cardiopulmonary bypass } \\
\hline$\leq 4 \mathrm{~h}$ & $4 / 79$ & .09 \\
\hline$>4 \mathrm{~h}$ & $5 / 35$ & \\
\hline \multicolumn{3}{|l|}{ Postoperative stroke } \\
\hline Yes & $2 / 11$ & .18 \\
\hline No & $7 / 103$ & \\
\hline \multicolumn{3}{|l|}{ Hypertension } \\
\hline Yes & 9/99 & .22 \\
\hline No & $0 / 15$ & \\
\hline \multicolumn{3}{|l|}{ Coronary artery disease } \\
\hline Yes & $4 / 35$ & .42 \\
\hline No & $5 / 73$ & \\
\hline \multicolumn{3}{|l|}{ Cerebral artery disease } \\
\hline Yes & $2 / 26$ & .96 \\
\hline No & $6 / 81$ & \\
\hline \multicolumn{3}{|l|}{ Diabetes } \\
\hline Yes & $3 / 12$ & .01 \\
\hline No & $5 / 101$ & \\
\hline \multicolumn{3}{|l|}{ Hyperuricemia } \\
\hline Yes & $0 / 3$ & .27 \\
\hline No & $9 / 110$ & \\
\hline \multicolumn{3}{|l|}{$\begin{array}{l}\text { Chronic obstructive } \\
\text { pulmonary disease }\end{array}$} \\
\hline Yes & $4 / 15$ & .0006 \\
\hline No & $3 / 93$ & \\
\hline \multicolumn{3}{|l|}{ Smoking } \\
\hline Yes & $4 / 36$ & .18 \\
\hline No & $3 / 70$ & \\
\hline
\end{tabular}

(6/37) associated with emergency operations $(P=.12)$. Eight $(7.0 \%)$ patients had transient neurologic dysfunction. Other complications were respiratory failure in $17(14.9 \%)$ patients, bleeding in $6(5.3 \%)$, gastrointestinal tract problems in $3(2.6 \%)$, and mediastinitis in $1(8.8 \%)$.

Table 1 shows the results of univariate analysis of risk factors for hospital deaths, and Table 2 shows those of univariate analysis of risk factors for stroke. Tables 3 and 4 show the results of multivariate analysis of risk factors for hospital death and perioperative stroke. 
TABLE 2. Univariate analysis of risk factors for stroke

\begin{tabular}{|c|c|c|}
\hline Variables & No. & $P$ value \\
\hline \multicolumn{3}{|l|}{ Operation } \\
\hline Total arch replacement & $9 / 74$ & .21 \\
\hline Hemiarch replacement & $2 / 40$ & \\
\hline \multicolumn{3}{|l|}{ Urgency } \\
\hline Elective & $5 / 76$ & .12 \\
\hline Emergency & $6 / 38$ & \\
\hline \multicolumn{3}{|l|}{ Concomitant operations } \\
\hline Yes & $4 / 41$ & .98 \\
\hline No & $7 / 73$ & \\
\hline \multicolumn{3}{|l|}{ Circulatory arrest } \\
\hline$>60 \min$ & $5 / 42$ & .53 \\
\hline$\leq 60 \min$ & $6 / 72$ & \\
\hline \multicolumn{3}{|l|}{ Cardiopulmonary bypass } \\
\hline$\leq 4 \mathrm{~h}$ & $5 / 35$ & .26 \\
\hline$>4 \mathrm{~h}$ & $6 / 79$ & \\
\hline \multicolumn{3}{|l|}{ Cardiac ischemic time } \\
\hline$\leq 3 \mathrm{~h}$ & $10 / 98$ & .62 \\
\hline$>3 \mathrm{~h}$ & $1 / 16$ & \\
\hline \multicolumn{3}{|l|}{ Hypertension } \\
\hline Yes & $10 / 99$ & .67 \\
\hline No & $1 / 15$ & \\
\hline \multicolumn{3}{|l|}{ Coronary artery disease } \\
\hline Yes & $4 / 35$ & .59 \\
\hline No & $6 / 73$ & \\
\hline \multicolumn{3}{|l|}{ Cerebral artery disease } \\
\hline Yes & $3 / 26$ & .66 \\
\hline No & $7 / 81$ & \\
\hline \multicolumn{3}{|l|}{ Diabetes } \\
\hline Yes & $1 / 12$ & .86 \\
\hline No & $10 / 101$ & \\
\hline \multicolumn{3}{|l|}{ Hyperuricemia } \\
\hline Yes & $0 / 3$ & .56 \\
\hline No & $11 / 110$ & \\
\hline \multicolumn{3}{|l|}{$\begin{array}{l}\text { Chronic obstructive } \\
\text { pulmonary disease }\end{array}$} \\
\hline Yes & $2 / 15$ & .56 \\
\hline No & $8 / 93$ & \\
\hline \multicolumn{3}{|l|}{ Smoking } \\
\hline Yes & $5 / 36$ & .26 \\
\hline No & $5 / 70$ & \\
\hline
\end{tabular}

The mean follow-up was $2.3 \pm 2.0$ years. Figure 3 shows the postoperative survival curve. The postoperative 1-year survival was $84.8 \%$, the 3-year survival was $68.5 \%$, and the 5 -year survival was $58.1 \%$.

\section{DISCUSSION}

Advances in perioperative care, anesthesia management, myocardial and brain protection during surgery, and sophis-

TABLE 3. Multivariate analysis of risk factors for hospital death

\begin{tabular}{lccc}
\hline & $\boldsymbol{P}$ value & Odds & $\mathbf{9 5} \% \mathbf{C I}$ \\
\hline COPD & .013 & 8.48 & $1.6-46.0$ \\
\hline
\end{tabular}

$C I$, Confidence interval; $C O P D$, chronic obstructive pulmonary disease.
TABLE 4. Multivariate analysis of risk factors for stroke

\begin{tabular}{lccc}
\hline & $\boldsymbol{P}$ value & Odds & $\mathbf{9 5 \%} \mathbf{C I}$ \\
\hline Urgency & .029 & 4.62 & $1.2-18.2$ \\
\hline CI, Confidence interval. & & &
\end{tabular}

ticated techniques have resulted in favorable results of cardiac surgery in octogenarians. ${ }^{2,3}$ However, aortic arch surgery, which requires hypothermia and circulatory arrest, is still an invasive intervention. The number of octogenarians undergoing aortic surgery in our institute has been steadily increasing. The reasons are the increase in average life expectancy and the extension of the surgical indication. The surgical outcome of aortic arch surgery is improving recently, ${ }^{4}$ and it is natural to extend the surgical indication to the patients of more advanced age with aortic disease.

Previous reports from our institute described that from 1991 to 1997 the postoperative mortality of septuagenarians and octogenarians after thoracic aortic surgery was $15.6 \% .^{5}$ In this study, although the population was limited to octogenarians, the mortality rate was low; even more, it decreased to $4.5 \%$ after 2002 .

The reason for the recent improvement of surgical results is not simple, but one of the major recent modifications of the surgical strategy is brain protection. For brain protection, RCP and ASCP were respectively used before 2000. Although deep hypothermia has usually been used for brain protection, the availability of ASCP has led to recent trends toward use of moderate hypothermia together with circulatory arrest. ${ }^{6-10}$ We have used ASCP with circulatory arrest

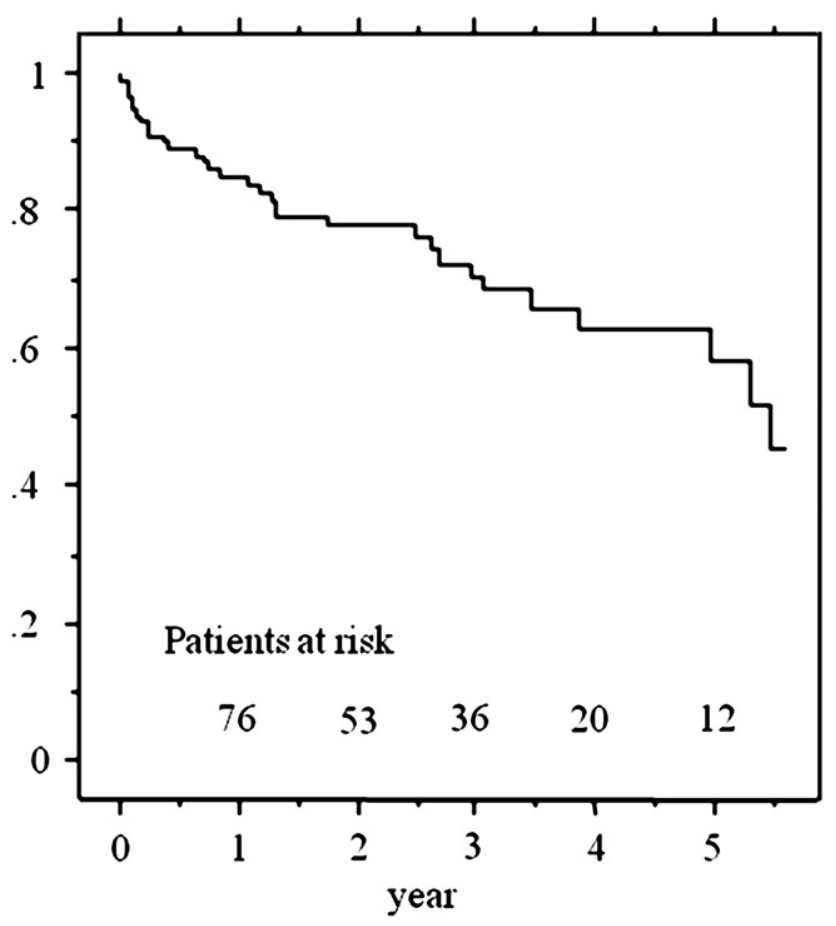

FIGURE 3. Postoperative survival curve. 
as the standard technique since 2001, because ASCP yielded better results than RCP under circulatory arrest in our institute. ${ }^{11}$ The system used for cerebral perfusion has gradually been modified, and right axillary cannulation is now a routine maneuver. ${ }^{12,13}$ In addition, since 2002 we have gradually elevated the temperature of hypothermic circulatory arrest from $20^{\circ} \mathrm{C}$ to $28^{\circ} \mathrm{C}$ for aortic arch surgery, as noted above. ${ }^{14}$

The ratio of emergency operations in this study was more than $30 \%$. Acute aortic dissection is not easy to prevent, but early recognition and treatment of asymptomatic large aneurysms in octogenarians might be possible. Our indication for elective aortic arch surgery in octogenarians is essentially the same as that for younger patients. When patients can still carry out their activities of daily living, even in the ninth decade of life, we believe the patient is in condition to survive an aortic arch operation.

Whether an emergency surgical procedure for acute aortic dissection should be done in octogenarians is controversial. ${ }^{15-17}$ In this series, 28 patients were operated on to treat acute aortic dissection and the hospital mortality rate was $10.7 \%$. Our indication for acute aortic dissection in octogenarians is also the same as for younger patients. Unless the patient has severe preoperative brain damage, we believe the patient has a good chance to survive.

Kirsch and his colleagues ${ }^{18}$ reported that the actuarial survival was $79.2 \%$ at 1 year, $9 \%$ at 3 years, and $56.2 \%$ at 5 years after cardiac surgical procedures in octogenarians. Melby and his colleagues ${ }^{3}$ reported the actuarial survival was $82 \%$ at 1 year, $70 \%$ at 3 years, and $56 \%$ at 5 years after aortic valve replacement in octogenarians. Aortic arch surgery is still one of the most invasive procedures in cardiovascular surgery. The survivals found in this study, however, are comparable with those mentioned above.

In conclusion, the results of conventional aortic arch surgery in octogenarians are improving. The operations were performed with an acceptable operative risk even under emergency situations, including acute aortic dissection. The option of conventional surgery for aortic arch diseases in octogenarians should not be abandoned only because of the high chronologic age of the patients.

\section{References}

1. Specer G. US Bureau of the Census: Projections of the population of the United States by age and race; 1988 to 2080. Washington, DC: US Government Printing Office; 1989. Current Population Reports; Series P-25; No.1018.
2. Alexander KP, Anstrom KJ, Muhlbaier LH, Grosswald RD, Smith PK, Jones RH, Peterson ED. Outcomes of cardiac surgery in patients $>$ or $=80$ years: results from the National Cardiovascular Network. J Am Coll Cardiol. 2000 Mar 1; 35(3):731-8.

3. Melby SJ, Zierer A, Kaiser SP, Guthrie TJ, Keune JD, Schuessler RB, Pasque MK, Lawton JS, Moazami N, Moon MR, Damiano RJ Jr. Aortic valve replacement in octogenarians: risk factors for early and late mortality. Ann Thorac Surg. 2007 May;83(5):1651-6; discussion 1656-7.

4. Minatoya K, Ogino H, Matsuda H, Sasaki H, Yagihara T, Kitamura S. Surgical management of distal arch aneurysm: another approach with improved results. Ann Thorac Surg. 2006 Apr;81(4):1353-6; discussion 1356-7.

5. Okita Y, Ando M, Minatoya K, Tagusari O, Kitamura S, Nakajjma N, Takamoto S. Early and long-term results of surgery for aneurysms of the thoracic aorta in septuagenarians and octogenarians. Eur J Cardiothorac Surg. 1999 Sep; $16(3): 317-23$

6. Bachet J, Guilmet D, Goudot B, Dreyfus GD, Delentdecker P, Brodaty D, Dubois C. Antegrade cerebral perfusion with cold blood: a 13-year experience. Ann Thorac Surg. 1999 Jun;67(6):1874-8; discussion 1891-4.

7. Kazui T, Inoue N, Yamada O, Komatsu S. Selective cerebral perfusion during operation for aneurysms of the aortic arch: a reassessment. Ann Thorac Surg. 1992 Jan;53(1):109-14.

8. Dossche KM, Morshuis WJ, Schepens MA, Waanders FG. Bilateral antegrade selective cerebral perfusion during surgery on the proximal thoracic aorta. Eur J Cardiothorac Surg. 2000 Apr;17(4):462-7.

9. Jacobs MJ, de Mol BA, Veldman DJ. Aortic arch and proximal supraaortic arterial repair under continuous antegrade cerebral perfusion and moderate hypothermia. Cardiovasc Surg. 2001 Aug;9(4):396-402.

10. Di Bartolomeo R, Di Eusanio M, Pacini D, Pagliaro M, Savini C, Nocchi A Pierangeli A. Antegrade selective cerebral perfusion during surgery of the thoracic aorta: risk analysis. Eur J Cardiothorac Surg. 2001 Jun;19(6):765-70.

11. Okita Y, Minatoya K, Tagusari O, Ando M, Nagatsuka K, Kitamura S. Prospective comparative study of brain protection in total aortic arch replacement: deep hypothermic circulatory arrest with retrograde cerebral perfusion or selective antegrade cerebral perfusion. Ann Thorac Surg. 2001 Jul;72(1):72-9.

12. Numata S, Ogino H, Sasaki H, Hanafusa Y, Hirata M, Ando M, Kitamura S. Total arch replacement using antegrade selective cerebral perfusion with right axillary artery perfusion. Eur J Cardiothorac Surg. 2003 May;23(5):771-5; discussion 775 .

13. Ogino H, Sasaki H, Minatoya K, Matsuda H, Tanaka H, Watanuki H, Ando M Kitamura S. Evolving arch surgery using integrated antegrade selective cerebral perfusion: impact of axillary artery perfusion. J Thorac Cardiovasc Surg. 2008 Sep;136(3):641-8; discussion 948-9.

14. Minatoya K, Ogino H, Matsuda H, Sasaki H, Tanaka H, Kobayashi J, Yagihara T, Kitamura S. Evolving selective cerebral perfusion for aortic arch replacement: high flow rate with moderate hypothermic circulatory arrest. Ann Thorac Surg. 2008 Dec;86(6):1827-31.

15. Neri E, Toscano T, Massetti M, Capannini G, Carone E, Tucci E, Diciolla F, Scolletta S, Morello R, Sassi C. Operation for acute type A aortic dissection in octogenarians: is it justified? J Thorac Cardiovasc Surg. 2001 Feb;121(2):259-67.

16. Shiono M, Hata M, Sezai A, Iida M, Yagi S, Negishi N. Emergency surgery for acute type a aortic dissection in octogenarians. Ann Thorac Surg. 2006 Aug; 82(2):554-9.

17. Hata M, Sezai A, Niino T, Yoda M, Unosawa S, Furukawa N, Osaka S, Murakami T, Minami K. Should emergency surgical intervention be performed for an octogenarian with type A acute aortic dissection? J Thorac Cardiovasc Surg. 2008 May;135(5):1042-6.

18. Kirsch M, Guesnier L, LeBesnerais P, Hillion ML, Debauchez M, Seguin J, Loisance DY. Cardiac operations in octogenarians: perioperative risk factors for death and impaired autonomy. Ann Thorac Surg. 1998 Jul;66(1):60-7. 